\title{
ENSINAR NA DOCÊNCIA UNIVERSITÁRIA: INDÍCIOS DA IN- TEGRAÇÃO ENSINO E PESQUISA
}

TEACHING IN UNIVERSITY: evidence of the integration between teaching and research

\author{
ENSEÑAR EN LA CARRERA UNIVERSITARIA: evidencia de la integración de la \\ enseñanza y la investigación
}

\author{
Isabel Maria Sabino de Farias \\ Doutora em Educação pela Universidade Federal do Ceará (UFC) \\ Professora do Curso de Pedagogia e do Programa de Pós-Graduação em Educação (Mestrado e Doutorado) da UECE. \\ isabel.sabino@uece.br
}

Silvina Pimentel Silva Doutorado em Educação Brasileira (2008) - UFC e Pós-Doutorado pela Universidade de Brasília - UnB (2013). Professora assistente da Universidade Estadual do Ceará. silvinapimentel@yahoo.com.br

\begin{abstract}
RESUMO: Docentes universitários que pesquisam possuem um modo diferenciado de ensinar? A interrogação permeia as análises deste artigo, que discute a integração ensino e pesquisa com base em estudo empírico com professores que mantêm vínculo com a atividade de pesquisa no exercício da docência na Educação Superior. Argumenta sobre a natureza epistêmica do ensinar e sua interface com a pesquisa, compreendida como indissociável da aprendizagem. Descreve a prática de ensino de cinco professores da Medicina, Biologia, Educação Física, Enfermagem e Física, evidenciando elementos que ancoram suas decisões. Identificou uma racionalidade prática no modo de ensinar dos professores pesquisados, desdobrada, por diferentes caminhos, na preocupação com o aluno. PALAVRAS-CHAVE: Ensino Superior. Práticas pedagógicas. Aprendizagem da docência. Pesquisa. Formação docente.
\end{abstract}

ABSTRACT: University professors who research have a different way of teaching? The question permeates the analyzes in this article, which discusses the integration of teaching and research based on empirical study with professors who maintain ties with the research activity in the practice of teaching in Higher Education. Argues about the epistemic nature of teaching and its interface with the research, understood as inseparable from learning. Describes the teaching practice of five professors of Medicine, Biology, Physical Education, Nursing and Physics, highlighting elements that anchor their decisions. The research Identified a practical rationality in the way that the professors surveyed teaches, outspread in different ways in the concern with the student.

KEYWORDS: Higher education. Pedagogical practices. Teaching learning. Research. Teacher training.

RESUMEN: ¿Maestros universitarios que pesquisan tienen un modo diferente de enseñanza? La interrogación impregna los análisis en este artículo, que trata de la integración entre enseñanza y la investigación basada en el estudio empírico con los maestros que mantienen vínculos con la actividad de investigación en la práctica de la enseñanza en la Educación Superior. Discute la naturaleza epistémica de la enseñanza y su interrelación con la investigación, comprendida como inseparable de la aprendizaje. Describe la práctica de la enseñanza de cinco profesores de Medicina, Biología, Educación Física, Enfermería y Física, destacando los elementos que anclan sus decisiones. Identificada una racionalidad práctica en la manera de enseñanza de los maestros encuestados, desplegada de distintas maneras, en la preocupación con el estudiante.

PALABRAS CLAVE: Educación Superior. Prácticas pedagógicas. Enseñanza-aprendizaje. Investigación. Formación de maestros. 
ENSINAR NA DOCÊNCIA | Isabel Maria Sabino de Farias e Silvina Pimentel Silva

\section{1 | INTRODUÇÃO}

O mundo do professor universitário apresenta-se como objeto de investigação emergente neste início de século $\mathrm{XXI}$, no que tem assumido relevante papel a produção editorial recente sobre a pedagogia universitária, campo epistemológico em construção. Com efeito, a prática pedagógica do professor universitário constitui temática central nos estudos desse campo, uma vez que a aproximação ao que acontece na aula, à ação didática do professor, tem possibilitado a produção de conhecimento sobre esse processo.

Que formação é necessária para o exercício da docência na educação superior? Como profissionais que atuam na universidade aprendem e se desenvolvem como docentes? Que elementos epistemológicos fundamentam as decisões pedagógicas no exercício da função docente na universidade? Questões desta ordem não derivam de um exercício meramente retórico, uma vez que ainda hoje a lógica de contratação dos docentes universitários se apoia na premissa de que quem sabe fazer sabe ensinar (CUNHA, 2009).

A compreensão desse processo remete a situação de atraso cultural que nutre a educação brasileira, provocando lentas mudanças na efetivação de suas intenções. No curso da evolução de sua história "a escola organizada no Estado oligárquico não é a escola organizada na sociedade nacionalista ou nas sociedades de hoje" (FERNANDES, 1995, p.15). Nesse contexto, as reformas educacionais arregimentadas pelo Estado incorporam as dificuldades e expressam os interesses destas épocas, atreladas às proposições dos projetos de desenvolvimento implementados.

A cada reforma do ensino, as instituições formadoras assumem novas funções. Com a revolução industrial e capitalista, começaram a ocupar funções antes atribuídas à família. Nesse movimento, ampliou-se seu papel, indo de formadora da força de trabalho à criação de um exército de reserva. Formadora de indivíduos para aceitarem a sociedade do modo como está organizada e também aprender a conviver serenamente com novas formas de dependência impostas pelas necessidades dos seus modelos de desenvolvimento (FERNANDES, 1995). Este movimento, obviamente, se desenvolveu permeado por embates e contradições, as quais certamente respondem por situações paradoxais como a atualmente vivenciada pelos professores universitários.

Esses profissionais têm como atribuição atuar no ensino, na pesquisa e na extensão. Assunto polêmico, pois há severas críticas quanto ao desenvolvimento de ações nessas esferas, argumentando-se que prevalecem as de ensino. Com efeito, o ensino voltado para a formação de profissionais destaca-se historicamente como função que marca a emergência da educação superior no Brasil. À revelia dessa tradição, é corrente o reconhecimento de que no contexto acadêmico a pesquisa se sobressai como ação mais valorizada, perspectiva igualmente presente nos demais espaços sociais.

Esta situação tem movido estudos que interpelam sobre a relação pesquisa e ensino com o objetivo de tensionar a hegemonia do discurso que postula a docência e a pesquisa como "atividades complementares e que mutuamente se beneficiam" (RAMSDEN; MOSES, 1992, p. 273). Em meio a argumentos céticos e defesas calorosas, não há como negar que a discussão sobre a relação ensino e pesquisa compõe o rol das temáticas polissêmicas e controversas da atualidade. O tema demanda estudos empíricos que possam trazer novos indícios, no que pretende contribuir as reflexões sistematizadas neste texto, que tem como objetivo discutir o sentido da investigação e da reflexão no espaço da docência universitária como possibilidade de integração ensino e pesquisa em contextos de formação.

Em busca de compreender possibilidades e dilemas da integração ensino e pesquisa na prática pedagógica do professor universitário apresenta-se um recorte dos resultados de um ciclo de es- 
tudos empíricos acerca do assunto, envolvendo dezoito docentes de dez cursos de graduação, de uma universidade pública (FARIAS, 2008, 2011, 2013). Iniciativa apoiada pelo Conselho Nacional de Desenvolvimento Científico e Tecnológico (CNPq) e a Fundação Cearense de Apoio ao Desenvolvimento Científico e Tecnológico (FUNCAP) no período de 2008 a 2013. Para este escrito, a atenção recaiu sobre cinco professores identificados com experiência consolidada de pesquisa, noção que considerou as seguintes características: qualificação, mínima, de doutor; desenvolvimento de projetos de pesquisa; inserção em programas de iniciação científica; atuação em grupos de pesquisa; inserção e/ou contribuição para criação de programas de graduação e pósgraduação; continuada produção científica. Sob esta ótica, a expressão experiência consolidada de pesquisa faz referência ao docente que, pelo conjunto das vinculações estabelecidas no seu percurso profissional com atividade de pesquisa, evidencia autonomia, regularidade, maturidade intelectual e reconhecimento dos pares como pesquisador (FARIAS, 2013). Os cinco docentes, vinculados a cursos distintos, foram observados em situação de aula e entrevistados.

De início, as análises ressaltam a natureza epistêmica do ensinar, bem como sua interface coma pesquisa, relação compreendida como dimensões indissociáveis da aprendizagem. Prosseguem destacando a prática de ensino de cinco professores atuantes nos cursos de Medicina, Ciências Biológicas, Educação Física, Enfermagem e Física de uma universidade pública, buscando evidenciar os elementos que fundamentam suas decisões pedagógicas no contexto do ensino.

\section{2 | 0 “SABER ENSINAR”: um fazer-saber epistêmico}

O ensinar é atividade secular no contexto das diversas sociedades, porém as discussões em torno das questões a ele pertinentes não gozam do status de assunto resolvido. Muito pelo contrário, continua incluso no rol das polêmicas que exigem revisitação permanente e aprofundamento para saber o que acontece e como resolver as diversas problemáticas inerentes em seu acontecimento, em particular, nos espaços formais de ensino. Estado, família, instituições formadoras, professores e alunos são os atores principais das ações que envolvem os processos de educação e escolarização de crianças e adultos, como direito de todos, independentes da classe social, gênero, etnia e raça.

O objeto fundamental do ensino é o conteúdo das diversas áreas do conhecimento, mais precisamente os conhecimentos específicos (da história, da geografia, da matemática, das ciências físicas e biológicas, da língua portuguesa, etc.) e os das ciências da educação, compreendendo a pedagogia, psicologia, filosofia, sociologia, antropologia para elencar somente algumas delas. Nestas últimas estão as teorias que embasam as formas de apropriação dos conhecimentos das diversas ciências em contexto das práticas da sala de aula, mediadas pelos professores, seja na conversão do conhecimento em saber escolar, seja nas questões que envolvem aspectos afetivos, cognitivos e psicomotores.

Em geral, os professores que exercem atividades docentes no contexto universitário são mestres e doutores, alguns inclusive com estágio pós-doutoral, portanto, portadores da titulação legalmente necessária para atuar no nível superior do ensino. Espera-se destes, minimamente, o domínio de conhecimentos sobre metodologia de pesquisa, o conteúdo das disciplinas que ministram, bem como os métodos que envolvem os procedimentos didáticos que subsidiam suas práticas educativas.

Embora a atuação profissional do professor da Educação Superior esteja ancorada na tríade ensino, pesquisa e extensão, o que se verifica é a não articulação entre essas atividades no exercício da docência neste contexto, registrando-se a prevalência de uma ou outra (ensino e extensão; ensino e pesquisa; pesquisa e ensino, etc.). O crescimento da preocupação com a for- 
mação de professores para atuar neste nível da educação nacional é relativamente recente, resultante dos processos de organização e lutas arquitetadas no seio dos movimentos sociais contemporâneos. A qualificação profissional para exercer as atividades de ensino historicamente é uma questão polêmica. Nas últimas décadas, contudo, tornou-se assunto merecedor de maior atenção frente aos desafios enfrentados com a acelerada complexificação do mundo do trabalho. Cabe às instituições formadoras cuidar da formação dos profissionais que ocuparão diversas profissões, papel atribuído em maior escala às universidades.

Vincula-se a essa compreensão que a prática de docentes universitários sem vínculo direto com atividades de pesquisa no exercício da docência em contextos da prática e, em cumprimento das orientações legais e curriculares que indicam a pesquisa como princípio de formação em cursos de graduação, reflita negativamente no ensino que desenvolvem (SILVA, 2008). Tais formulações levam a suspeitar de uma provável infertilidade de práticas pedagógicas desvinculadas da pesquisa, um atributo necessário à qualidade da formação dos professores.

Assim entendendo, defende-se a necessária articulação entre ensino e pesquisa no desenvolvimento do currículo de formação em contextos da prática, se reconhecida os efeitos da ausência da pesquisa para formação docente. Esse entendimento amplia as ideias de se buscar uma formação calcada no pensar, na reflexividade, no diálogo, na descoberta, fundados em concepções que extrapolam a mera transmissão de conhecimentos prontos e acabados nos diversos níveis da escolarização.

Em diversos países, o ensino com pesquisas é uma prática largamente incentivada. Cuba desenvolve ensino apoiado na pesquisa, desde a Educação Infantil, extensivo aos demais níveis. Na Alemanha, por exemplo, "essa prática é antiga e se pode expressar que é uma atitude normal do educador alemão pensar, junto com seus alunos, no desenvolvimento de qualquer atividade de ensino que se realize" (TRIVIÑOS, 2003, p.12). No Brasil, essa preocupação aparece, aproximadamente, na década de 80 do século $X X$, embora nas universidades o anúncio do ensino com pesquisa tenha a idade da universidade alemã ao definir ensino, pesquisa e extensão como função dessas instituições, mesmo que não concretizadas.

Imergir na esfera desta problemática comporta realizar reflexões acerca da formação desenvolvida no espaço da pedagogia universitária, temática abordada recorrentemente por diversos pesquisadores no Brasil, em particular, para tratar das práticas de ensino de professores com lastro na tradição pedagógica inspirada na racionalidade técnico-instrumental. No caso particular dessa discussão o foco é entender a natureza do ensino de professores que têm experiências com pesquisa no cumprimento da docência na Educação Superior, no exercício de suas atividades docentes em sala de aula. Compete perguntar: que tipo de ensino esses professores tem propiciado aos que se formam?

\section{3 | COMO ENSINAM PROFESSORES QUE PESQUISAM?}

Embora nas últimas décadas o universo da sala de aula e da prática de ensino dos professores tenha alcançado visibilidade na investigação educacional, pouco ainda se sabe sobre o que acontece na aula universitária e o modo de ensinar de seus professores, sobretudo daqueles com experiência consolidada de pesquisa. Esta expressão faz referência ao docente que, pelo conjunto das vinculações estabelecidas no seu percurso profissional com atividades de pesquisa, evidencia autonomia, regularidade, maturidade intelectual e reconhecimento dos pares como pesquisador. Neste sentido, foram consideradas as seguintes características:

a) qualificação, mínima, de doutor;

b) desenvolvimento de projetos; 
c) inserção em programa de iniciação científica;

d) atuação em grupos de pesquisa;

e) inserção e/ou contribuição para criação de programas de graduação e pós-graduação;

f) continuada produção científica.

Compreende-se que um docente não faz o que bem quer e entende. Sua ação profissional encontra-se orientada por compromissos institucionais e legais mais amplos; é estruturada por fins e relações que se reportam a exigências sociais, políticas, epistemológicas e pedagógicas (FARIAS, 2000). Neste sentido, ensinar é uma prática situada e ética, cujas decisões traduzem

uma intencionalidade. É esta intencionalidade que move a ação docente. O professor quando delibera, o faz apoiado nas teorias e experiências que tecem seu compromisso com sua função social, posição forjada mediante a concepção que ele tem das relações entre educação, sociedade e conhecimento.

Corrobora-se, assim, a formulação de Veiga (1989), de que aula representa a concretude do trabalho docente propriamente dito, pois é nela que o processo didático intencional que caracteriza o ensinar se materializa, ganha sentido. É neste espaço-tempo coletivo de formação e produção de conhecimento que a interação professor-aluno, dimensão mais visível do ensino, se concretiza.

Com efeito, o que acontece na sala de aula advém da previsão da ação e da análise do alcance dos fins determinados. Planejar e avaliar são dimensões fundamentais do ensino e, segundo Montero (2001, p. 149), são "potencialmente mais susceptíveis de ser consideradas como oportunidades para a elaboração de conhecimento sobre o ensino pelos professores". Assim, considerando-se o intuito de saber como ensinam professores com vínculo com pesquisa, buscou-se identificar elementos estruturantes do agir profissional desses docentes universitários a partir de suas perspectivas acerca de sua ação didática e do seu planejamento. Ao manifestar-se sobre como planeja e desenvolve suas aulas, o docente universitário revela elementos que estruturam seu pensar e fazer, conferem sentido à sua prática profissional, enfim, seu modo de ser professor universitário, questões tratadas nos próximos tópicos.

\section{4 | ENSINAR NO CURSO DE MEDICINA}

Dos cinco professores participantes desta análise somente o professor do curso de Medicina é bacharel, possuindo quase 25 anos de experiência docente em universidades nacionais e internacionais, aqui nominado de professor Pedro. Os registros presentes em seu CV Lattes evidenciam intenso desenvolvimento de projetos de pesquisa, com atuação em institutos pesquisa em diversos países. É líder de grupo de pesquisa cadastrado no diretório do CNPq há 14 anos, tem experiência com orientação (iniciação científica, mestrado e doutorado).

Este professor ao relatar sobre sua ação didática explicita alguns elementos que norteiam seu agir profissional. Afirma que ao organizar a sua disciplina a preocupação é que o conteúdo de sua disciplina tenha "realmente uma maior eficácia para estudantes de medicina". É evidente em seus depoimentos a importância que atribui à aprendizagem dos discentes e expressa seu cuidado para assegurar ao graduando um conhecimento importante e útil para sua futura atuação profissional, portanto fala da necessidade de adequar o conteúdo a ser ensinado ao alunado capaz de promover uma interface entre objetivos de ensino, conteúdo e forma. Ao esclarecer sobre como desenvolve sua ação, professor Pedro afirma "partir de problemas concretos que o médico vive" (Pedro - Curso Medicina). E por isso, em função dos objetivos de cada aula, utiliza metodologias particulares.

Registra esse professor que reconhece as questões pedagógicas relativas ao "que ensinar", 
ENSINAR NA DOCÊNCIA | Isabel Maria Sabino de Farias e Silvina Pimentel Silva

"como ensinar" e "para que ensinar" como importantes e amparadas por uma ação reflexiva sobre o que é melhor para o aluno, considerando a finalidade da formação universitária, a maturidade intelectual do discente e as condições concretas de trabalho. Na observação de suas aulas identificamos que se preocupa por concretizar as intenções que norteiam e organizam sua ação didática. Sinaliza ser adepto de uma prática dialógica, favorável à negociação com os alunos. O professor demonstra segurança no encaminhamento das decisões, explora os conhecimentos prévios dos discentes, articula bem os conceitos, revela respeito aos graduandos, incentiva a valorização da disciplina, em face da tendência do alunado de dar maior importância às disciplinas clínicas. O exercício de questionar, provocar e estabelecer associações entre a vida cotidiana e o conhecimento científico também evidenciaram que o professor reconhece os saberes do aluno, validando a sua fala, concordando ou complementando-as.

Em uma das aulas observadas, o professor provocou a simulação de um caso clínico. Esta atividade tornou-se um exercício de reflexão, serviu para integrar a turma e possibilitou o levantamento de hipóteses, a troca de ideias, opiniões e saberes entre os alunos, propiciou a discussão e socialização dos pontos de vista divergentes entre os participantes de cada equipe e entre aqueles que apresentaram diferentes soluções para o caso clínico em análise. Ao final, o professor registrou a sua satisfação, elogiou e continuou indagando sobre os assuntos da aula.

Embora bacharel, o professor Pedro revela sensibilidade pedagógica e maturidade profissional como docente, demonstrando que suas decisões não são improvisadas, mas centradas no aluno e norteadas pelos objetivos formativos que definem o perfil do médico egresso do curso. Declarou que costuma adotar metodologias que propiciem um aprendizado experiencial, referentes a "conteúdos que podem ser úteis para a prática médica no cotidiano".

Importa frisar, em relação ao modo de ensinar e de iniciar o aluno no processo de construção do conhecimento, que o professor observado demonstra cuidado com a participação ativa dos alunos, embora reconheça a dificuldade de atingir esses objetivos em decorrência das restrições do contexto de trabalho. Reclama que a maioria das aulas fica limitada ao espaço da sala de aula, ao uso de um computador e um projetor, recurso didático básico e recorrente em suas aulas. As aulas expositivas evidenciaram forte presença. Embora o cenário de trabalho na universidade favoreça a realização desse tipo de aula, a prática pedagógica deste professor registra a adoção de exposições dialogadas, marcadas pelo exercício da pergunta, de reflexões a partir de situações do cotidiano, exemplificações, entre outros procedimentos. Outra estratégia de ensino explorada pelo mesmo professor é o debate entre os próprios alunos por meio de trabalhos em grupo, estudo de casos, mesmo não se constituindo em novidades ou práticas inovadoras.

O registro do uso de estratégias de ensino do tipo estudo de caso reforça uma tradição na formação profissional de nível superior desde meados do século XIX, conforme informa Amaral (2013). Mesmo assim, as contribuições, desse tipo de estratégia, residem na oportunidade de explorar uma situação - real ou fictícia - para discuti-la coletivamente. Além dos estudos de casos, o professor ressalta que utiliza em suas aulas o 'jogo de papéis' (ou 'role play'). Entende essa metodologia como diferente, pois inicia com uma introdução do assunto seguida da prática. Faz uso da técnica 'jogo de papéis', por considerar que situa o aluno de modo mais ativo na aprendizagem.

As estratégias adotadas pelo professor do curso de Medicina dão ênfase à aprendizagem experiencial, estimulando processos de associação e construção do conhecimento, enfoque que defende a integração entre as "teorias que promovem a aprendizagem por associação, debitárias do empiricismo, e as teorias da aprendizagem por reestruturação, de base construtivista" (POZO, 2002, p. 53). Declara valer-se não de uma prova tradicional, mas da aplicação dos conteúdos trabalhados durante a disciplina: "Então é uma avaliação que procura não somente avaliar conheci- 
ENSINAR NA DOCÊNCIA | Isabel Maria Sabino de Farias e Silvina Pimentel Silva

mentos adquiridos, mas aplicação desses conhecimentos na prática a partir de casos concretos". (Pedro - Curso Medicina).

Este docente tem como preocupação desenvolver um ensino problematizador, que possibilite o conflito cognitivo, a valorização dos conhecimentos prévios, a reelaboração dos aprendizados. Esta tendência, na análise de Formosinho (2009), é coerente com o campo específico da formação médica, profissão "de desenvolvimento humano". Depreende-se que o professor Pedro adota uma abordagem que conjuga conhecimentos de áreas disciplinares afins (antropologia, psicologia, ciências sociais, por exemplo) para compreender e intervir adequadamente nos problemas de saúde com os quais um médico lida em seu cotidiano de trabalho.

Em seu discurso, há evidência de domínio do campo conceitual, ao mesmo tempo em que cobra de seus alunos consistência teórica nas elaborações e argumentações. Estas características de seu modo de ensinar, entretanto, não estão explicitamente associadas ao propósito de propiciar ao aluno construir conhecimento, como se aprender não implicasse também, e de alguma maneira, produzir conhecimento. Deste posicionamento se intui que a iniciação do aluno na construção do conhecimento é associada diretamente à pesquisa em tempos e ambientes específicos, no caso, o grupo de pesquisa. Embora em sala de aula dedique atenção ao fomento da atitude de crítica, da análise, da comparação, da associação, habilidades investigativas básicas presentes na elaboração de conhecimento, denota uma acepção mais próxima da transmissão e da reprodução.

Mesmo tendendo a associar a construção do conhecimento e o desenvolvimento da atitude investigativa principalmente à pesquisa acadêmico-científica, não há negação da possibilidade de sua integração ao ensino. Professor Pedro faz menção a momentos de atividades práticas como o role play, considerando permitir coletar dados, estabelecer pontos de vista, avaliar processos, desenvolver habilidades de observação etc. propícias à aprendizagem de conceitos e também de conhecer como um pesquisador trabalha. Considera essa estratégia de ensino como propícia à realização de experiências de investigação sobre o ensino. Informou ter realizado com os alunos uma "investigação de nossas próprias aulas", cujo registro resultou na publicação, com os alunos, de dois artigos na Revista Brasileira de Educação Médica. Reforça: "Estudamos sobre nós mesmos... Eu acho que a maioria dos alunos participou como "objetos de pesquisa", mas alguns deles foram pesquisadores da própria dinâmica educacional". (Pedro - Curso Medicina, grifo do autor).

Mesmo não fazendo menção ao ensino com pesquisa como estratégia adotada, a experiência relatada evidencia esforço em propiciar oportunidades pedagógicas de iniciação dos alunos com algumas práticas de pesquisa integradas ao ensino. Segundo Lampert (2008), o ensino com pesquisa reveste-se de três etapas: o questionamento, marcado pela dúvida como geradora de conhecimento à medida que favorece o exercício de problematização, de formulação e reformulação de ideias, conceitos, princípios; a argumentação, caracterizada pela busca da teoria como substrato explicativo e que possibilita encaminhar as questões suscitadas; a comunicação, momento voltado para a socialização dos resultados da análise. Estas etapas estão presentes na experiência desenvolvida em sala de aula pelo professor Pedro.

Desse modo, seus posicionamentos acerca de como inicia o aluno no processo de construção do conhecimento e de como promove o desenvolvimento de atitude investigativa sinalizam para uma concepção científico-acadêmica de pesquisa relacionada à coleta de dados, à análise, à avaliação etc., manifesta, sobretudo, na valorização de atividades práticas que oportunizem ao aluno desenvolver habilidades similares às de um pesquisador no decurso de uma investigação. Esta compreensão, por sua vez, exprime uma tensão entre a prática pedagógica e a concepção de pesquisa explicitada nos posicionamentos destacados, não associada explicitamente à adoção da pesquisa como princípio formativo norteador do agir como docente. 
Nas observações das aulas, assim como nos depoimentos do professor sobre a prática, existe demonstração de um modo de ensinar não improvisado, evidências de um amplo domínio teórico e prático de seu campo disciplinar de conhecimento, característica da expertise de pesquisador demonstrada nas decisões e ações pedagógicas destinadas à promoção da aprendizagem discente.

\section{5 | O ENSINAR NO CURSO DE BIOLOGIA}

O professor do curso de Ciências Biológicas que participou desta pesquisa, sendo observado em suas aulas e entrevistado, doravante será identificado de professor Nilson. É bacharel em engenharia florestal com licenciatura em engenharia agrícola, atuando há 13 anos como docente universitário, mas seu trabalho com pesquisa se intensificou a partir de 2004. É líder de grupo de pesquisa, orienta bolsistas de iniciação científica e mestrado. $O$ ensino não aparece no seu $C V$ Lattes como objeto de investigação e publicação.

Este professor ao ser interpelado sobre como realiza suas aulas destaca o foco no aluno, precisamente na essencialidade da disciplina, na preparação do aluno para o mercado de trabalho e/ou investir na continuidade de sua formação acadêmica. Este horizonte aparece em seu depoimento como força motriz de suas decisões para organizar o processo didático, evidenciando que mesmo sendo licenciado e atuando em um curso cujo objetivo é formar professores seu pensamento e ação estão voltados para a formação do bacharel.

Diferentes tipos de práticas delineiam o modo como este professor desenvolve sua ação didática. Privilegia a articulação entre as aulas teóricas e práticas vivenciadas na disciplina como objeto de avaliação. Nesse sentido, considera a participação em excursões (aulas de campo) e em atividades de laboratório (aulas práticas), a produção de relatório científico, a realização de seminários, a formulação e análise de problemas ambientais, além da prova escrita individual. É sua preocupação assegurar aos estudantes experiências significativas e provocadoras de curiosidade, do espírito crítico e da atitude investigativa que se espera de um pesquisador.

Prevalece, não seria impertinente afirmar, um entendimento tácito de que a aprendizagem da docência decorre de um processo imitativo, pelo exemplo dado pelo professor formador. Este componente, de inegável importância na aprendizagem da profissão, não é suficiente e pode ter efeitos nem sempre benéficos, conforme asseveram Formosinho (2009) e Nóvoa (2009).

O saber da experiência é destacado como referente a como o professor foi constituindo um modo particular de exercer a docência, de conceber e desenvolver sua ação profissional. Reconhece "a prática", no saber da experiência, como eixo fundante do modo constituído de ensinar, confirmando estudos como o de Therrien (1996), Tardif, Lessard e Lahaye (1991). Estes últimos nomeiam como saber de experiência o "conjunto de saberes, de representações a partir das quais os docentes interpretam, compreendem e orientam sua profissão e sua prática quotidiana em todas as suas dimensões" (TARDIF; LESSARD; LAHAYE, 1991, p. 228). São saberes produzidos a partir da história escolar, da relação com os professores enquanto discentes, da trajetória profissional nas diversas instituições em que lecionou, bem como os advindos do cotidiano docente. $O$ saber da experiência é oriundo "da" e "pela" prática. Therrien (1996, p.14) o caracteriza como um "saber adquirido em situação", num "contexto de interação" e cunhado por uma dimensão "subjetiva e coletiva" no seu processo de elaboração.

A falta de uma formação pedagógica mais sólida é reconhecida, ressaltando a contribuição da disciplina de Metodologia do Ensino Superior, realizada na pós-graduação stricto sensu, na qualificação de sua ação didática. Repudiou a falta de apoio institucional, seja na oferta de formação continuada para seus docentes, seja na garantia de condições de trabalho mais favoráveis, regis- 
tro que converge com o posicionamento do professor de medicina. Mesmo enfrentando esses desafios, professor Nilson revela o uso diversificado de estratégias de ensino no processo de iniciação do aluno na construção do conhecimento e no desenvolvimento da atitude investigativa. Refere-se a seminários, à formulação de problemas, a estudos dirigidos e à elaboração de resumos, visando o aprofundamento, o fomento a sistematização das análises e ao desenvolvimento de habilidades investigativas.

Este docente, assim como Dalben (2013), reconhece a importância da pergunta e dos problemas na construção dos processos de aprendizagem e de ensino. Questionar, problematizar e buscar soluções, entendidos como elementos de uma melhor aprendizagem, asseguram dinamicidade, colocam o aprendente no centro do processo, despertam a curiosidade e a criticidade, favorecendo a capacidade de intervenção e de elaboração própria, pois as "capacidades mediadoras e mobilizadoras dos problemas permitirão a construção de interações mais dialógicas em sala de aula, movidas pelos desejos de aprender" (DALBEN, 2013, p. 71). Contudo, pesquisar aparece, no depoimento do professor Nilson, como atividade especializada e reservada a um espaço específico, o grupo de pesquisa, o laboratório; ele não a vislumbra como princípio formativo, por conseguinte, como dimensão indissociável da aprendizagem (FARIAS ABU-EL-HAJ; LEITINHO; CARDOSO, 2012).

Este professor apresenta uma ação didática planejada, centrada e favorável à aprendizagem do aluno numa perspectiva que valoriza o conhecimento do campo disciplinar e a atitude crítica e investigativa; desenvolve um ensino problematizador, fortemente permeado por sua experiência de pesquisa.

\section{6 | ENSINAR NO CURSO DE FÍSICA}

O participante desta área na pesquisa, nomeado aqui de professor Cláudio, é licenciado, possui pós-doutorado, pertence aos quadros da instituição em análise desde 2005, atua na graduação e no Mestrado em Ciências Físicas Aplicadas. Tem experiência com vários projetos de pesquisa e, atualmente, é integrante de dois grupos de pesquisa.

A proposta atual do curso de Física define que a formação de seus egressos, independente de sua área de atuação, deve apoiar-se em "conhecimentos sólidos atualizados em física" (BRASIL, 2001, p. 3). Ainda segundo as diretrizes deste curso, a atitude de investigação deve estar sempre presente, embora associada a diferentes formas e objetivos de trabalho. Define o licenciado como físico-educador.

Professor Cláudio manifesta a sua identidade e amorosidade com a física, apresentando-se como um estudioso dessa área. A docência em física, pelo tom de seu relato, aparece como desdobramento e tarefa que um apaixonado pela área não poderia se furtar. As suas explicações sobre como ensina assumem o tom de justificativa, ao anunciar: "Não tive bons professores que me preparassem para dar aulas" (Cláudio - Curso de Física). Ao fazer este comentário, trata do planejamento de suas aulas destacando a ementa como elemento balizador do que precisa ser ensinado e, pelo seu posicionamento, não cabe questionamento. Ele afirma não planejar suas aulas previamente; a organização de sua prática em sala de aula ocorre de maneira espontânea e improvisada, orientada pelo conhecimento disciplinar que acredita deter, revelando uma concepção de planejamento burocrática e tecnicista. Não reconhece a necessidade de planejar, além de considerar que para dar aula: "Basta um quadro, um piloto e a coisa acontece". (Cláudio - Curso de Física).

Na descrição de sua prática de ensino evidencia o conteúdo como elemento didático que move sua ação em situação de aula, configurando um processo de ensino centrado na transmissão e 
na responsabilização do aluno pela possibilidade ou não de aprender. Esse professor não reconhece seu papel mediador nesse processo, evidenciando um agir profissional ancorado numa racionalidade instrumental ao dizer: "Eu ensinei; aprender é com eles". (Cláudio - Curso de Física).

Da forma como se apresenta no relato do professor Cláudio, a assertiva de que "aprender é com ele [o aluno]" baseia-se no entendimento de que se alguns conseguem aprender, tendo acesso à mesma aula que os demais, o aluno que não logra êxito é porque não se esforça o suficiente em estudar o conteúdo. O seu entendimento é emblemático dessa racionalidade, expresso na afirmação: "Tenho alguns alunos que não querem nada, atrapalham as aulas [...]. Apresentam muita dificuldade em raciocínio e trabalhar isso é atrasar cronograma, deixar de dar conteúdo. O cumprimento do programa é o que caracteriza um bom trabalho docente". (Cláudio - Curso de Física, grifo do autor).

Ao registrar fragilidades no seu preparo como docente acrescenta: "Tenho reproduzido nos últimos dez anos o que meus mestres me ensinaram". A assertiva confirma constatações como a de Cortesã (2000, p. 40), de que os "docentes universitários geralmente ensinam como foram ensinados", também alinha-se às advertências de Formosinho (2009) acerca dos efeitos da prática docente dos formadores, destacada como "importantes modelos de aprendizagem da profissão". Do ponto de vista epistemológico, da produção do conhecimento, esta compreensão do processo de ensino tem implicações sobre o desenvolvimento da atitude investigativa nos alunos como favorável a uma formação docente reflexiva e orientada por interesses emancipatórios. Na perspectiva do professor Cláudio, ensinar vincula-se à transmissão, ao repasse de conteúdos percebidos como legítimos socialmente. Aprender, por sua vez, está associado à reprodução.

Neste sentido, ele não vislumbra, pelo menos em seu relato e nas aulas observadas, a relação pesquisa e ensino como dimensões indissociáveis da aprendizagem. Para este professor "pesquisar é produzir ciência, inovação, principalmente na área de física; já no ensino preparamos para esse momento, o de pesquisar". Formar pesquisadores aparece como intencionalidade que mobiliza seus esforços. Categoricamente afirma: "Eu ensino para que meus alunos façam pesquisa. Afinal, ensinar é uma coisa, pesquisar é mais complexo, requer método de investigação" (Cláudio - Curso de Física). O lugar da pesquisa para este docente é o laboratório, espaço de aplicação de conceitos transmitidos em aula. É deste modo que entende a possibilidade de integração do ensino à pesquisa. Esta perspectiva, obviamente, não envolve todos os alunos: "Nas aulas práticas no laboratório, meus alunos conseguem aplicar o que eu ensino, principalmente meus alunos de iniciação científica". (Cláudio - Curso de Física).

Presume-se que este professor seja adepto de um ensino prescritivo, que desvaloriza o conhecimento pedagógico como componente de sua profissionalidade docente. Sua compreensão do ensino nega-o como dimensão relevante de produção do conhecimento; revela domínio do campo disciplinar e acredita que este conhecimento é suficiente para ensinar.

\section{7 | ENSINAR NO CURSO DE EDUCAÇÃO FÍSICA}

Uma jovem professora, cujo CV Lattes revela uma trajetória de formação e inserção no mundo profissional da Educação Física intensa e precoce. Professora Ingrid, assim nomeada aqui, começou sua atuação como professora universitária em 2004, possui experiência com coordenação pedagógica de curso de graduação e de programas de formação docente. Também apresenta experiência como coordenadora de pesquisa, orienta bolsistas de iniciação cientifica e compõe o corpo docente de programa de pós-graduação relacionado à sua área de formação.

Professora Ingrid, ao discorrer sobre suas aulas, não faz referência ao projeto pedagógico do curso da instituição que trabalha, nem às diretrizes curriculares atualmente vigentes. Em seu rela- 
ENSINAR NA DOCÊNCIA | Isabel Maria Sabino de Farias e Silvina Pimentel Silva

to, mostra preocupação com "o que ensinar" e ao chegar à sala de aula com uma proposta planejada e organizada previamente, embora negocie com os alunos as possíveis alterações no programa. Relata que agenda data de atividades, faz acordos no sentido de assegurar continuidade e aprofundamento sequenciado do conteúdo do semestre.

Numa das aulas observadas, manifesta a preocupação da docente em tornar compreensível para os alunos o conteúdo a ser trabalhado na disciplina. Neste dia, iniciou esclarecendo o objetivo da aula, fez uma exposição do conteúdo usando slides, apresentou situações-problemas, entretanto, na maior parte das vezes, ela não ofereceu o momento de réplica para que os alunos respondessem as questões apresentadas. Atitude redutora da participação dos alunos, inibindo o processo de reflexão sobre o tema abordado. Nas demais aulas, o modo de ensinar assumiu configuração similar.

$\mathrm{Na}$ entrevista, ao abordar sobre as práticas desenvolvidas, fez alusão às dificuldades para conciliar teoria e prática, agravadas pela falta de condições estruturais do curso. Confirma-se o argumento de Hargreaves (2002) de que os professores também são produções de seus contextos de trabalho. Evidencia, no contexto de aula, uma visão dicotômica entre teoria e prática, manifestada na interação com os alunos em expressões como: "quando vocês forem fazer a prática, vocês vão entender". (Ingrid - Curso de Educação Física).

Aprender aparece nos relatos desta professora como processo de reestruturação, ultrapassando a acumulação e a memorização de conhecimentos prévios (POZO, 2002). Professora Ingrid, embora preocupada com o aluno e sua aprendizagem, tende a atribuir ao aluno à tarefa de progredir na construção do seu conhecimento, uma vez que considera seu modo de ensinar como constrangido pelas condições de trabalho que enfrenta. O foco em aspectos técnicos do conteúdo da disciplina se sobressai, notando-se a ausência de sua articulação às especificidades do espaço escolar, situação, aliás, desconsiderada pela professora.

No que concerne à iniciação do aluno no processo de construção do conhecimento, esta professora registra que sua prática pedagógica na disciplina Treinamento Desportivo II "está muito longe do que considera ideal". (Ingrid - Curso de Educação Física). Mesmo evidenciando uma visão dicotômica entre teoria e prática, essa docente afirma que integra pesquisa e ensino em sua ação didática no contexto da sala de aula, dizendo: "querendo ou não, tudo é integrado, ensino e pesquisa. Então, querendo ou não, em Fisiologia, tudo que a gente ensina, com certeza, foi baseado em pesquisa". (Ingrid - Curso de Educação Física).

Nas suas formulações, a professora distingue o ensinar do pesquisar. Realça, porém, uma das possibilidades de integração entre ensino e pesquisa na formação docente apontadas por André (2001), que consiste na inserção de resultados de pesquisa nas disciplinas que ministram, fomentando a discussão, a capacidade de análise e a geração de novas questões. Professora Ingrid reconhece essa estratégia como integradora, muito embora as aulas observadas não registrem indicações de leitura para aprofundamento ou discussões de pesquisas sobre temas correlacionados à disciplina ministrada.

O diálogo e as observações realizadas permitem dizer que a docente é engajada na sua tarefa de ensinar, demonstra habilidade na gestão das relações sóciocognitivas presentes na aula e possui domínio do seu campo disciplinar de formação. Estas características, associadas a sua experiência de pesquisadora, permeia e vem desenhando um modo particular de ensinar, muito embora com contornos que carecem de maior consistência. Considerando formulações como a de Benedito (1995), de que "o professor universitário aprende a sê-lo mediante um processo de socialização em parte intuitiva, autodidata [...] ou seguindo a rotina dos outros", é bom lembrar o que assevera: essa socialização profissional "é insuficiente".

Um ensino constrangido pelas condições de trabalho, mas assumido com engajamento, mar- 
ENSINAR NA DOCÊNCIA | Isabel Maria Sabino de Farias e Silvina Pimentel Silva

cado pela ênfase no conteúdo e pela preocupação com a aprendizagem discente. Estes, certamente, são traços definidores da prática pedagógica da professora Ingrid.

\section{8 | ENSINAR NO CURSO DE ENFERMAGEM}

Também licenciada, a professora, aqui nomeada por Lidiane, participante da pesquisa, é bolsista de produtividade em pesquisa do CNPq, atua no ensino superior há 16 anos, trabalhando em duas instituições públicas de ensino superior, com participação sistemática em projetos de pesquisas. Realizou estágio de pós-doutoramento em 2012. Exerce atividades de orientação na iniciação científica, mestrado e doutorado.

A imersão na sala da professora Lidiane, bem como seus relatos, evidenciam que a docente planeja sua ação didática, realiza aulas expositivas dialogadas, recheadas de exemplos e situações do cotidiano de trabalho do enfermeiro, bem como um intenso incentivo à leitura e ao aprofundamento teórico. Seu fazer pedagógico valoriza a aprendizagem experiencial, entendida como um processo de compreensão ativa por parte do sujeito aprendente.

Aprender é uma construção dinâmica, que chama a associação de conhecimentos prévios e a construção de novos conhecimentos, numa perspectiva evolutiva, reestruturadora, anuncia Pozo (2002). O posicionamento da professora aponta nessa direção. Este modo de agir se explicita ao responder sobre as estratégias de ensino usadas para iniciar o aluno no processo de construção do conhecimento e no desenvolvimento de habilidades investigativas: "Embora seja uma coisa batida eu acho que a repetição, a argumentação e tentar mostrar que todo conhecimento é parte de um conhecimento maior [...], servem para que o aluno venha argumentar e também para que monte o seu próprio esquema de conhecimento". (Lidiane. - Curso de Enfermagem, grifo do autor).

Professora Lidiane, pelo que se observou durante as aulas acompanhadas, denota habilidade particular em tornar ensinável o conteúdo da disciplina. Castanho (2007, p. 69) ao tratar do desenvolvimento de investigações sobre a pedagogia universitária destaca narrativas de estudantes de graduação sobre professores marcantes, constatando a valorização de docentes identificados como "muito competentes na transposição didática", ou seja, "na transmissão do conhecimento científico de modo muito pessoal e didático". Não obstante as referências a inúmeros "professores admiráveis", os registros revelavam que estes "bons professores trabalham ainda preponderantemente na perspectiva da reprodução do conhecimento", adverte Castanho (2007, p. 70).

Esta docente reconhece que "tenta", por meio de sua ação pedagógica, favorecer o desenvolvimento da atitude investigativa entre os alunos. Ao explicar sua posição expressa uma acepção científico acadêmica de pesquisa, enfatizando a participação em eventos científicos e a elaboração de trabalhos para publicação em periódicos. Esclarece, ainda, que "educar pela pesquisa dá muito trabalho". (Lidiane - Curso de Enfermagem).

A professora Lidiane demonstra que vem fazendo o que é possível no contexto de trabalho em que se encontra inserida, na busca de caminhos que promovam a iniciação do aluno no processo de construção do conhecimento, muito embora sua compreensão sobre o lugar da pesquisa e do ensino nesse processo revele tensões. Ela relata que gosta de ensinar, que a docência foi uma escolha consciente desde o princípio de sua atuação profissional, elemento de convergência com os professores dos Cursos de Medicina e de Ciências Biológicas. Nesse sentido, esclarece que não tem "a preocupação de ministrar aula e ir embora". Sua ação junto aos alunos evidencia que sua expertise de pesquisadora é presente nas decisões sobre "o que ensinar" e "como ensinar". Mostra, em seu modo de ensinar, comprometimento com a aprendizagem da profissão pelo graduando, futuro enfermeiro. 
ENSINAR NA DOCÊNCIA | Isabel Maria Sabino de Farias e Silvina Pimentel Silva

As práticas de ensino descritas neste escrito apresentam-se como constrangidas por condiçõe de trabalho difíceis, aspecto preocupante uma vez que a Educação Superior aparece como contexto marcante de socialização profissional dos docentes pesquisados.

\section{9 | INTEGRAR ENSINO E PESQUISA NA PRÁTICA PEDAGÓGICA UNIVERSITÁRIA: ainda um desafio}

$\mathrm{Na}$ análise da ação didática dos cinco professores com experiência consolidada de pesquisa foi possível identificar uma prática pedagógica compósita, tensionada por concepções de pesquisa, ensino e aprendizagem matizadas tanto por orientações técnicas quanto de caráter mais dialógico e emancipatório. A prevalência de uma ou outra racionalidade desenha indícios distintos entre as práticas pedagógicas analisadas.

Identificou-se práticas pedagógicas com forte presença de estratégias de problematização e de fomento na aprendizagem experiencial voltada para o desenvolvimento profissional do aluno. Práticas pedagógicas marcadas pela experiência de pesquisa de seus docentes e pelo domínio do conhecimento no campo disciplinar de formação; professores pesquisadores que ensinam contextualizando, questionando e lançando mão de atividades que favoreçam ao aluno refletir, argumentar, observar, comparar, estabelecer relações, produzir textos, enfim, elaborar uma compreensão crítica sobre sua futura profissão e seu papel.

Esta composição no modo de ensinar, presente, embora com diferenciações, na prática pedagógica dos professores dos cursos investigados, aponta a pesquisa como componente com potencialidade para gerar inovações na Pedagogia universitária, ensejando rupturas com a cultura pedagógica acadêmica de base técnico-instrumental ainda prevalente. Por outro lado, assumir a pesquisa como princípio formativo requer alterações substantivas no pensamento e no fazer docente, o que não é simples nem se faz sem apoio institucional e formação pedagógica; certamente uma decisão que se situa para além do plano individual.

Lacunas na formação pedagógica desses docentes respondem pela evidência, em suas práticas, de concepções difusas sobre a aprendizagem, que podem ser traduzidas como "praticar o conhecimento". Esta situação promove oscilações e tensiona, no professor, suas concepções de ensino e pesquisa, obstaculizando sua compreensão como dimensões indissociáveis da aprendizagem. Igualmente, dificultam o desenvolvimento de práticas mais robustas e inovadoras destinadas à iniciação do aluno na construção do conhecimento, concorrendo para a presença ainda de aulas expositivas dialogadas.

Os discursos e práticas pedagógicas observadas dos professores pesquisados nos cursos de medicina, enfermagem, ciências biológicas e educação física indicam que a construção do conhecimento profissional vem ocorrendo de maneira autodidata, por ensaio e erro. O saber de experiência aparece como central na aprendizagem da docência, sendo intensamente mobilizado e valorizado pelos professores pesquisadores nas decisões que movem sua prática pedagógica. São eles que dão suporte e conferem sentido a ação didática, pois fornecem um referente à luz do qual decidem sobre "para que ensinar", "o que ensinar" e "como ensinar". Este percurso, na universidade, é marcado pela solidão docente, acentuada pela ausência de apoio institucional, sobretudo de formação pedagógica continuada que enseje práticas efetivas de colaboração entre pares.

As análises evidenciam a presença de uma racionalidade prática no modo de ensinar dos professores universitários participantes do estudo, desdobrada, por diferentes caminhos, na preocupação com o aluno. 
ENSINAR NA DOCÊNCIA | Isabel Maria Sabino de Farias e Silvina Pimentel Silva

\section{Referências}

AMARAL, M. L. Casos de ensino e estudos de caso: técnicas para formar professores de qualidade. In: VEIGA, I. P. A. Novas tramas para as técnicas de ensino e estudo. Campinas: Papirus, 2013. p. 115-132.

ANDRÉ, M. E. D. A. O papel da pesquisa na formação e na prática dos professores. Campinas: Papirus, 2001.

BENEDITO, V. et al. La formación universitária a debate. Barcelona: Universidade de Barcelona, 1995.

BRASIL. Ministério da Educação. Parecer CNE/CES nº 1.304, aprovado em 6 de novembro de 2001. Diretrizes Nacionais Curriculares para os Cursos de Física. Diário Oficial da União. Brasília, DF, 7 dez. 2001.

CASTANHO, E. M. Pesquisa em pedagogia universitária. In: CUNHA, M. I. da (Org.). Reflexões e práticas em pedagogia universitária. Campinas: Papirus, 2007.

CORTESÃ, L. Ser professor: um ofício em risco de extinção?. Porto, Portugal: Afrontamento, 2000.

CUNHA, M. I. da. Inovações pedagógicas: o desafio da reconfiguração de saberes na docência universitária. In: PIMENTA, S. G.; ALMEIDA, M. I. de (Org.). Pedagogia universitária. São Paulo: Editora da USP, 2009. p. 211-236.

DALBEN, Â. I. L. de F. O ensino por meio da resolução de problemas. In: VEIGA, I. P. A. Novas tramas para as técnicas de ensino e estudo. Campinas: Papirus, 2013. p. 69-98.

FARIAS ABU-EL-HAJ, M.; LEITINHO, M. C.; CARDOSO, N. de S. O ensino com pesquisa: contextualização e reflexões metodológicas. In: FARIAS, I. M. S. de; NÓBREGA-THERRIEN, S. M.; CARVALHO, A. D. F. (Org.). Diálogos sobre formação de professores: olhares plurais. Teresina: EDUFPI, 2012. p. 21-32.

FARIAS, I. M. S. de. Docência no telensino: saberes e práticas. São Paulo: Annablume; Fortaleza: SECULT/ CE, 2000.

A cultura docente face à formação para a pesquisa: a gestão dos saberes na docência universitária. Fortaleza: UECE/EDUCAS, 2008. 38 p. (Projeto de pesquisa: Proposta aprovada pelo CNPq - Edital universal 2008).

A cultura docente face à formação para a pesquisa: a gestão dos saberes na docência universitária: relatório técnico final. Fortaleza: UECE/EDUCAS, 2011. 280 p.
. Como ensinam professores que pesquisam? Brasília, DF: UnB, 2013. 69 p. (Relatório de pesquisa do estágio Pós-doutoral do Programa de Pós-Graduação em Educação da UnB).

FERNANDES, V. N. Escola fundamental: uma denúncia e uma inspiração. In: VEIGA, I. P. A. V.; CARDOSO, M. H. F. C. (Org.). Escola fundamental currículo e ensino. 2. ed. Campinas: São Paulo, 1995.

FORMOSINHO, J. (Org.). Formação de professores: aprendizagem profissional e ação docente. Porto: Porto Editora, 2009.

HARGREAVES, A. et al. Aprendendo a mudar: o ensino para além dos conteúdos e da padronização. Porto Alegre: ARTMED, 2002.

LAMPERT, E. O ensino com pesquisa: desafios e perspectivas. Linhas Críticas, Brasília, DF, v. 14, n. 26, p. 131-150, 2008.

MONTERO, L. A construção do conhecimento profissional docente. Lisboa: Instituto Piaget, 2001.

NÓVOA, A. Professores: imagens do futuro presente. Lisboa: EDUCA, 2009.

POZO, J. I. Aprendizes e mestres: a nova cultura da aprendizagem. Porto Alegre: ARTMED, 2002.

RAMSDEN, P.; MOSES, I. Associations between research and teaching in Australian higher education. Higher Education, n. 23, p. 273-295, 1992.

SILVA, S. P. Histórias de formação em grupos de iniciação científica: trajetórias da UECE e da UFC (1985 a 2005). 2008. 212 f. Tese (Doutorado em Educação) Universidade Federal do Ceará, Fortaleza, 2008.

TARDIF, M.; LESSARD, C.; LAHAYE, L. Os professores face ao saber: esboço de uma problemática do saber docente. Teoria e Educação, v. 4, p. 215-233, 1991.

THERRIEN, J. Trabalho e saber: a interação no contexto da pós-modernidade. In: MARKERT, W. (Org.). Trabalho, qualificação e politecnia. Campinas: Papirus, 1996. p. 53-70.

TRIVIÑOS, A. N. S. (Org.). A formação do educador como pesquisador no mercosul/cone sul. Porto Alegre: UFRGS, 2003.

VEIGA, I. P. A. A prática pedagógica do professor de didática. Campinas: Papirus, 1989. 